\title{
المقدمة: Introduction
}

للطلاء الكهربي أهمية كبرى سو اء في المجالات الصناعية أو الفنية،

حيث يفيد في إضفاء ثزاءً جمالياً للعمل المعدني سواء المستخدم منها في المجالات الصناعية أو المجالات الفنية . ومن مميزات استخدام الطلاء الكهربي الحصول منه على طبقة رقيقة جداً منتظمة السمك وتقدر بالميكرون (1 مم = . . . ميكرون) ، و إنها تساعد في وقاية المعدن (العمل المعدني) من العوامل الجوية المختلفة وتأثثرها على المعدن المتمثل في ظاهرة تآكل المعادن سواء الكيميائي أو الاحتكاكي، و الصدأ Corrosion of metal

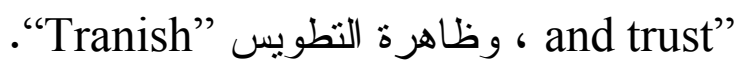

كما يعطي الطلاء الكهربي لأسطح الألومنيوم في العمل المعدني

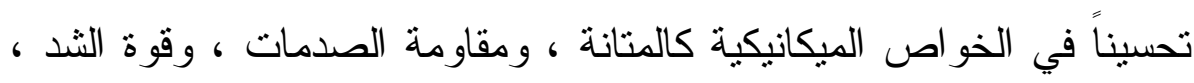
بالإضافة إلى تأثنيره الجمالي عليها. وكما يؤدي الطلاء إلى تحسين من الخواص الخاصة بجودة المنتجات (الاعمال المعدنية) من حيث تغطية الخدوش و الثقوب التي تتكون بالمعدن قبل أو أثناء مر احل التشغيل المختلفة. ومن الصعوبات الرئيسية لهذا البحث أن طبيعة فلز الألومنيوم أنه لا يقبل الطلاء عامة ، وذللك لسرعة تأكسد سطحه بالأكسجين الجوي ، إذ يكون

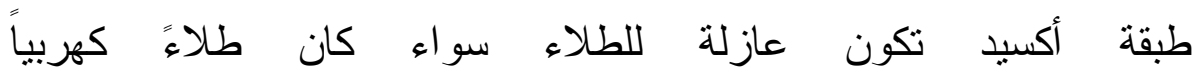

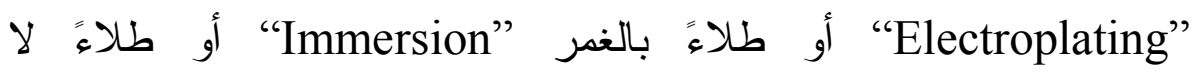
كهربيا”"Electroless plating" أو طلاءً بالإحلال بعر "Cemention" . Plating" 


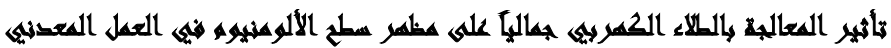

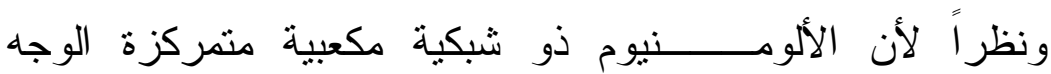

فإن معالجته بالطلاء الكهربي (F.C.C) "Faced Centered Cupic" يتطلب معالجات خاصة تتمثل في إكسابه طبقة وسيطة ما بين معدن الأساس للألومنيوم "Base Metal" و الطبقة التي سنترسب عليه و الناتجة عن طلائه كهربياً. و هذه الطبقة بعد أن قام الباحث بالدر اسة و التجريب نبين أنه تستخدم

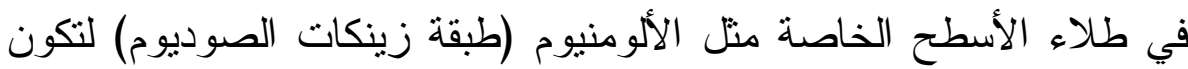

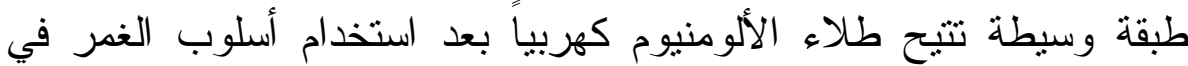
ترسيبها على معدن الأساس (الألومنيوم). ومن مميزات الطلاء الكهربي أنه يُكسب الألومنيوم خصائص أخرى جديدة غير خصائصه الطبيعية من حيث المظهر. وطريقة الطلاء الكهربي تعتبر من أفضل طرق التغطية من حيث التماسك و المظهر، حيث يتم التغطية بمواد فلزية ذات مظهر طبيعي تنيح إمكانية معالجتها بنفس الوسائل الثقتية من حيث التلميع الميكانيكي وخلافه ، كما أن الطلاء الكهربي يعطي نأثيرات لونية متعددة ومختلفة التأثير مثل

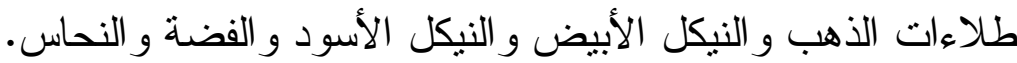

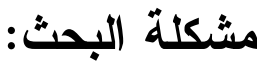

صعوبة إمكانية معالجة سطح الألومنيوم بالطلاء الكهربي، حيث أن الألومنيوم يعتبر من ضمن الأسطح المعنبة الخاصة و التي تتطلب استخدام

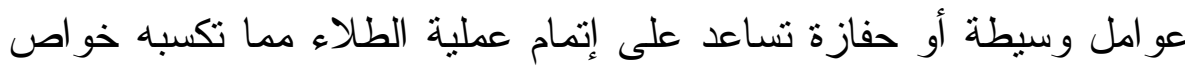
لونية جديدة تسهم في إثر اء العمل المعدني جمالياً ووظيفياً. 
إثراء أسطح الألومنيوم بالطلاء الكهربي بإضفاء ترسيات مختلفة

الألوان و المظهر و التي يمكن الاستفادة منها في إيجاد أساليب فنية جديدة تُشي مظهر العمل المعدني جمالياً ووظيفياً. أولا - نبذة مختصرة عن الألومنيوم:

الألومنيوم من المعادن الأكثز نشاطاً في الطبيعة ، ويوجد

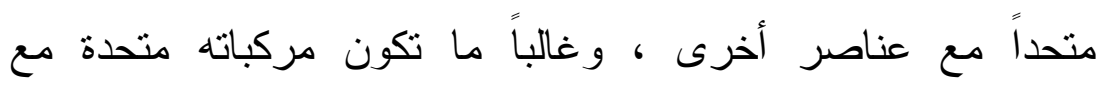
الأكسجين و السيليكون. ويحتل الألومنيوم المركز الثالث من بين العناصر وبنسبة ^^\% تقريباً ، وهو أكثر المعادن إنتشاراً في القثرة الأرضية ، وللألومنيوم عدة خو اص وهي:

ا - الخواص الطبيعية:

Sympol

Atonic number

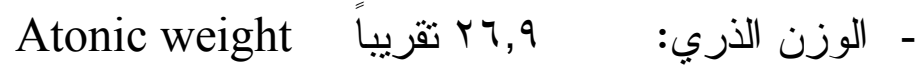

AL : - الرمز الكيميائي -

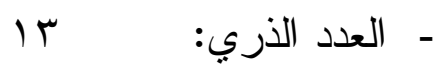
-

Colour أبيض فضي مائل للزرقة -

Melting point - درجة الإنصهار: ب7هم

Boiling point - درجة الغليان: - التوصيل الحراري: OV, • 


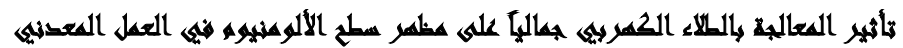

-

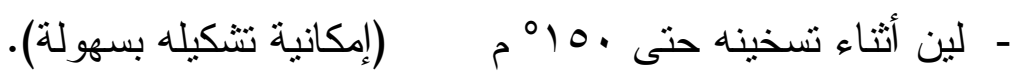

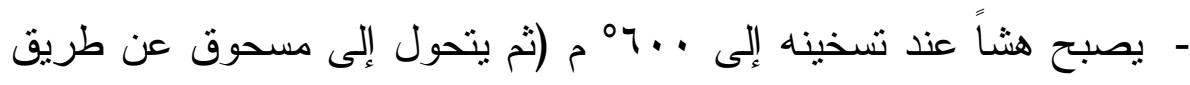
طنده

- ق قابل للطرق و السحب و التوصيل الجيد للحر ارة و الكهرباء.

- مقاوم للتآكل بفعل الهو اء الجوي ، وذذلك بواسطة طبقة الأكسيد المتكون

على سطحه بمجرد تعرضه للهو اء.

- البناء البللوري (النسق البللوري):

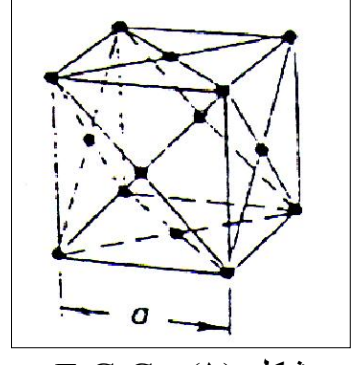

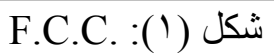

ذو شبكية مكعبية متمركزة الوجه

(F.C.C) "Faced Centered Cupic" ، وطول ضلع الثبكة ه., ــ انجستروم ،

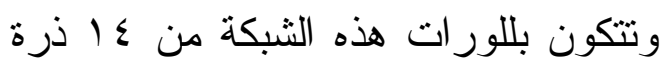

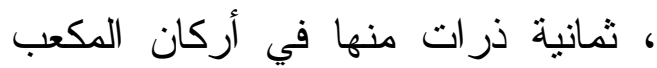

وستة ذرات كل منها في مركز كل وجها فيه لونه

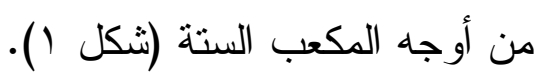

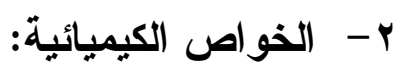

- - ليتميز الألومنيوم بتكوين طبقة رقيقة متماسكة على سطحه من

أكسيد الألومنيوم شديدة الإلتصاق ، ويعد هذا بمثابة حماية طبيعية له له لالكئل

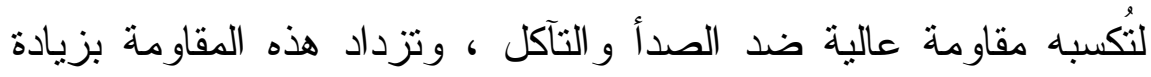




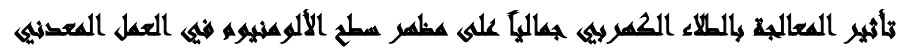

درجة نقاوته وقلة نسب الثوائب الداخلة في نركيبه" ('). كما أن هذه الطبقة هي التي تجعله ذو مظهر خامل.

- يمكن إذابة الألومنيوم في حمض النيتريك بإضافة كمية قليلة

من أملاح الزئق إلى الحمض مما يؤدي إلى تكوين آلاف الخلايا الجلفانية التي تعمل على إذابة الألومنيوم في الحمض ، ويتصاعد غاز الكيدروجين.

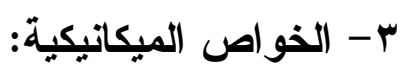

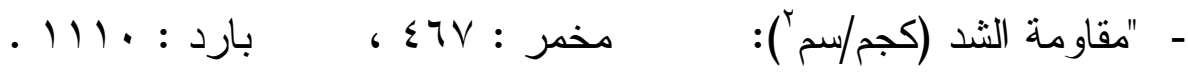

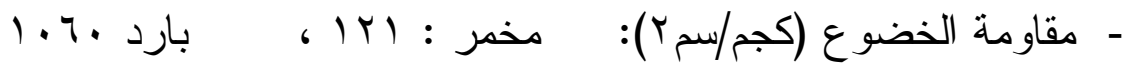

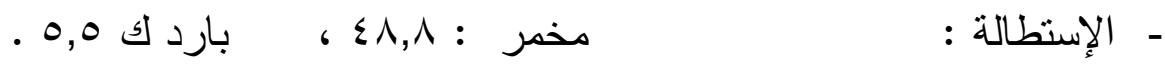

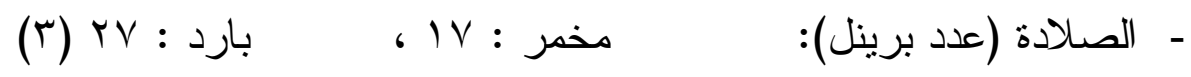

ثانيا - الطلاء الكهربي: Electroplating

ا - تعريف الطلاء الكهربي: Definition of Electroplating

"هو عملية لترسيب معدن على آخر كهربياً وفيها يمـرر تيــار

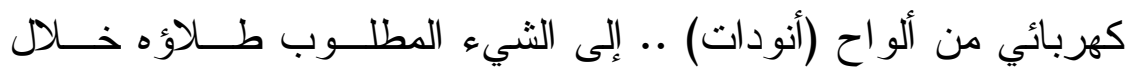

محلول ملحي معدني (الالكتروليت). وتتجذب أيونات هذا المعـدن إلـى

المنتجات المطلوب طلاؤها حيث تطلق شحناتها الكهربائية وتترسب على لى لئ

(السطح". (المنجات 


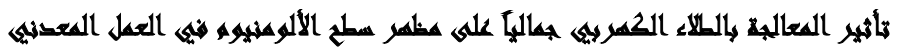

r

تتخلص هذه العملية في الآتي:

أ- "تجهيز محلول يحتوي على ملح مناسب من أمسـلاح الفلــز المطلـــوب

ترسيبه على السطح.

ب- غمر المنتجات المعدنية المر اد طلاؤها في المحلول الألكتروليتي مــع

توصيلها بالقطب السالب لمنبع التيار الكهربي المستمر مع اختيار جهد

مناسب وكثافة تيار مناسبة. وبذلك تصبح المنتجات المعدنية قطب سالب

ج- القطب المتصل بالطرف الموجب (الأنود) فإما أن يصنع من نفس الفلز

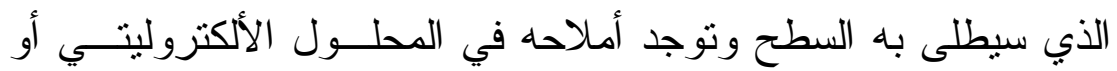

$$
\text { يصنع من فلز أخر. }
$$

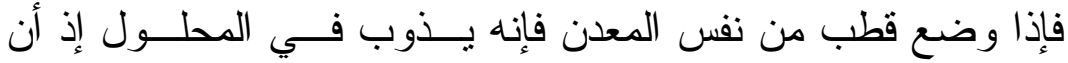

الذرات الموجودة على السطح تترك بعض الكتروناتها وتتحول إلى أيونــات موجبة تتنقل إلى المحلول حيث تحل محل الأيونات التي ترسبت على سطح الكانثود (المنتج المعدني) ثم تتنقل بدور ها إلى الكاثود حبـث تتعـادل هـى

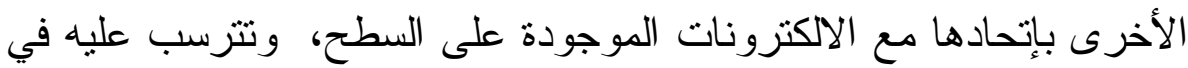
صورة ذرات من المعادن. وهكذا تستمر الدورة حيث تذوب ذرات من الأنود الادي في المحلول، وذر ات تترسب من المحلول على سطح الكانود.

أما في حالة نركيب أنود من معدن مختلف عـن الفــز الموجــودة

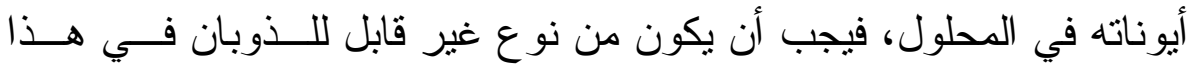

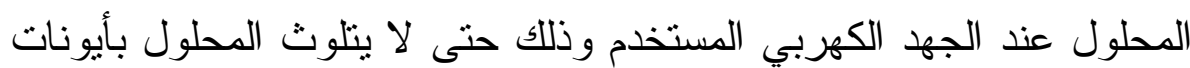




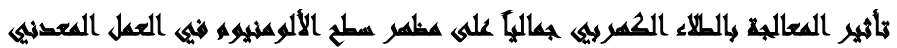

هذا المعدن، وما يترنب على ذللك من ترسب ذر اته على الســطح الجــاري

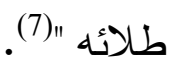

\section{تفسير ما يحدث في عملية الطلاء الكهربي:}

- "أثناء عملية التحليل الكهربي تكون كل الأيونات في المحلول تحمل التيار وتشترك بشكل تساهمي Contribution حيث تعتمد الأيونات الذائبة على

تركيز ها وقابليتها للحركة Mobility.

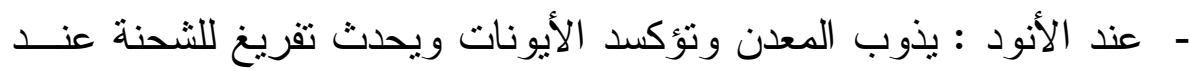

$$
\text { كل الكترود (قطب كهربي). }
$$

- عند الكاثود: تتز ايد الثحنات Positive Ions (الكاتيونات) وتختزل مـع

$$
\text { ترسب ذر ات الفلز ."(飞) }
$$

العوامل التي تحكم المظهر العام للســطح النــاتج بعـــ الترســيب

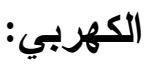

- شدة التيار المستخدم خلال عملية الطلاء. - - درجة نركيز المحلول المستخدم. - مرجة الحرارة. - - المو اد العالقة و الموجودة بالمحلول.

- الثق الحامضي أو القلوي المستخدم في عملية الطلاء الكهربي (لترسيب

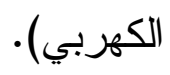




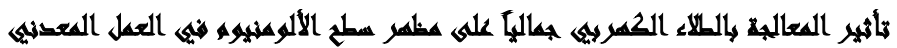

ثالثاً: تصميم التجربة: Experimental Design

- - - الخامات المستخدمة:

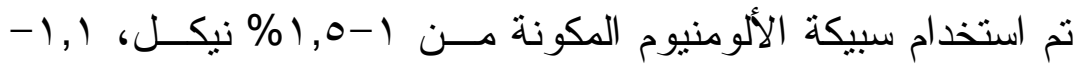

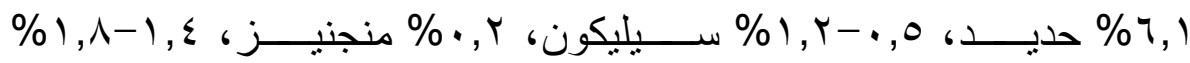

ماغنسيوم. و السبيكة تم استخدامها في شكل رقائق (ألو اح) بسمك ^, • مم

أ- تم تقطيع العينات بالمقاس س× سم، كما تم إجر اء العمليات الميكانيكيــة الخاصة بالتلميع وذلك باستخدام فرش ومو اتير التلميع وحجم العينة = 10

مفردة.

ب- ت تمهيز المحاليل الخاصة بعمليات الطلاءات المختلفة و التــي تـم حصر ها في الآتي:

* لاء النحاس الأحمر القلوي (القاعدي - السيانيدي).

* طلاء النحاس الأصفر القلوي.

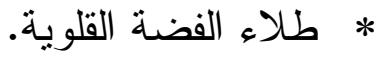

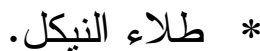

كما تم تجهيز محلول التتظيف الكيميائي.

Procedures ب إإجرات

أ-تم عمل التجهيز ات اللازمة للعينات بالمعالجة المسبقة من حيث التنظيف

الكيميائي و المعالجة القلوية dresing process ، حيث تم غمر العينات

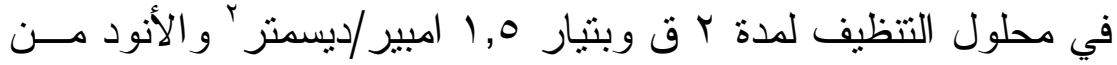




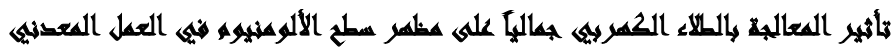

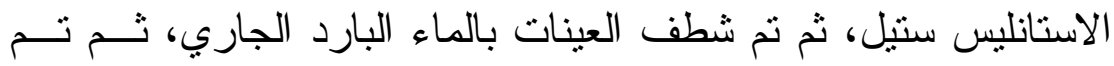

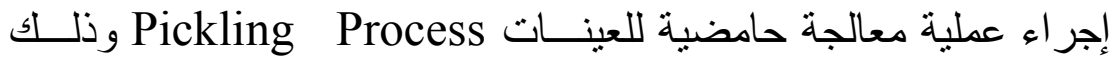

باستخدام حامض كبريتيك بتركيز • (1\%، وذللك لإجر اء معادلة القلــوي

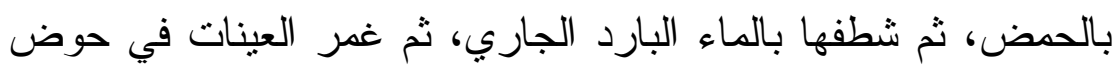

لمحلول زينكات الصوديوم لإكسابها الطبقة الوسيطة التي تقبل الطلاء ،

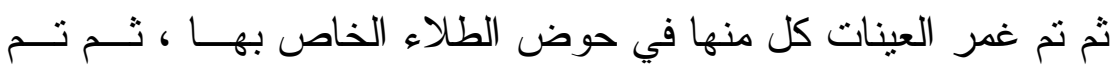

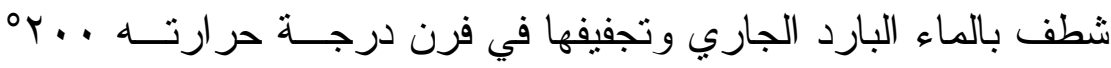

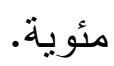

ب- تم استخدام سلسلة الطلاء الكهربي والمتكونة من حوض التنظيـف

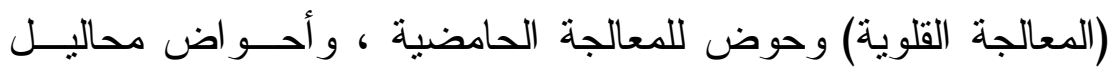

الطلاءات المختلفة وعمليات التجفيف.

r- المحاليل المستخدمة في عمليات الطلاء:

أ- محلول النتظيف:

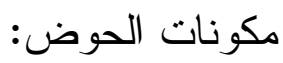

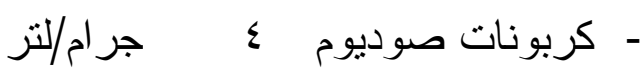

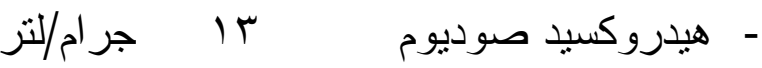

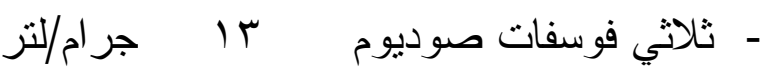

- 1 لتر - ماء

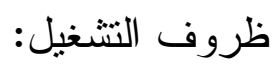

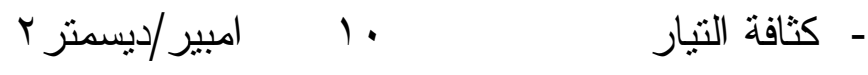




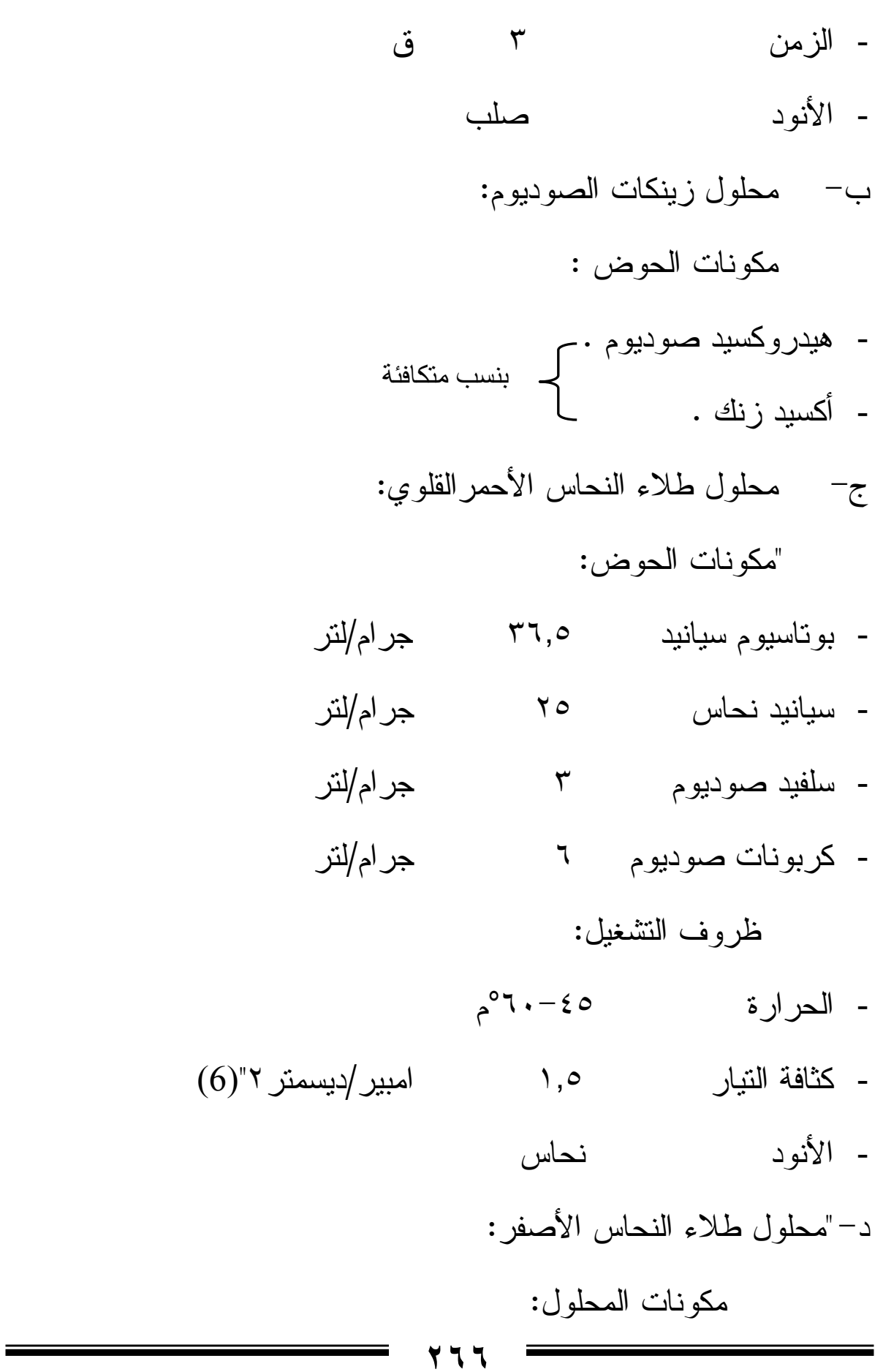




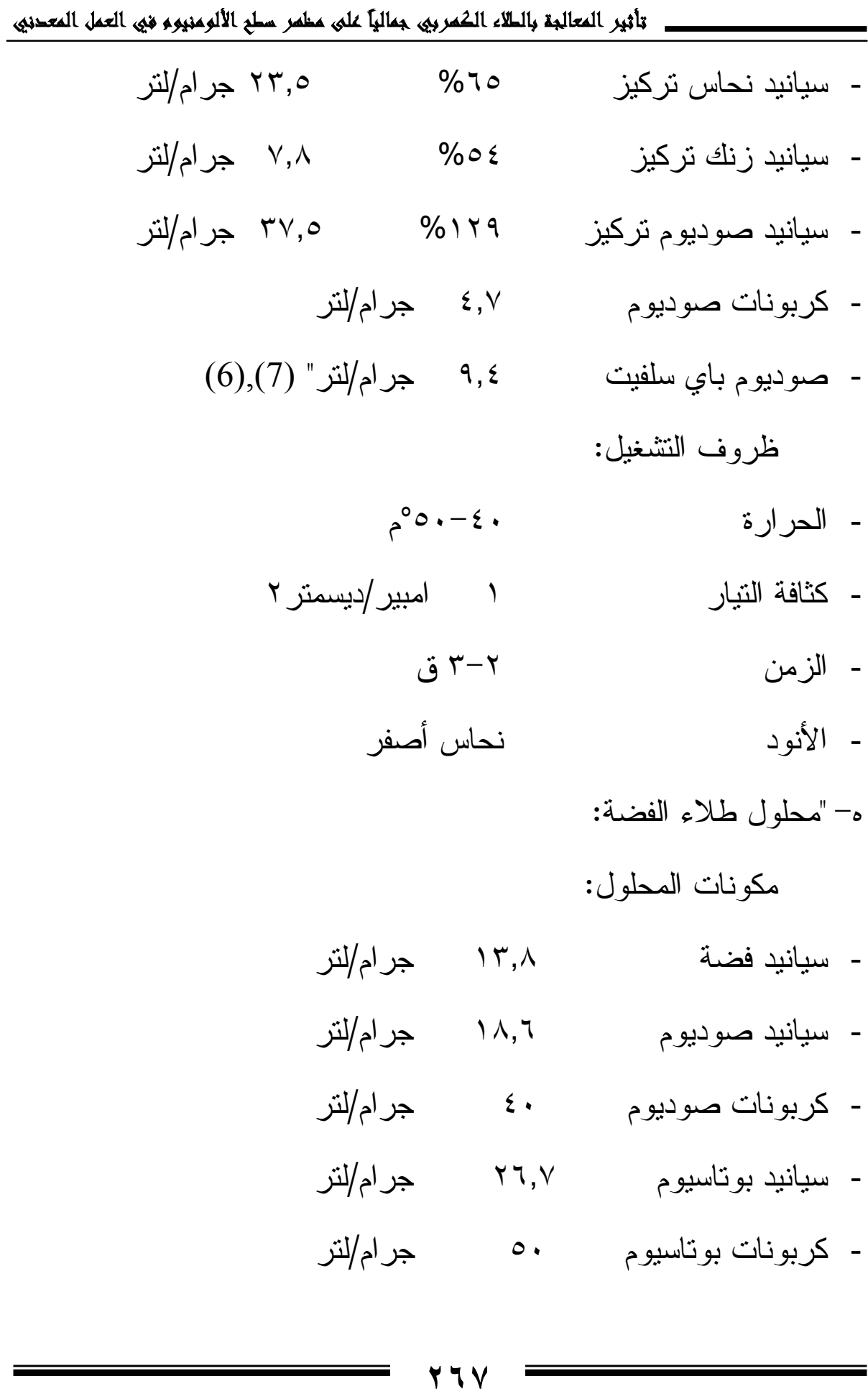




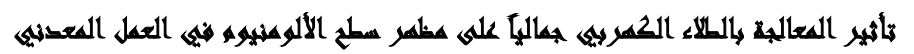

$$
\text { ظروف التشغيل: }
$$

-

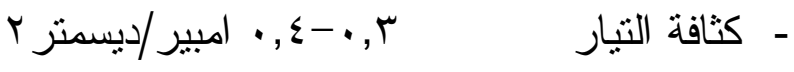

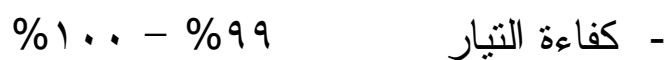

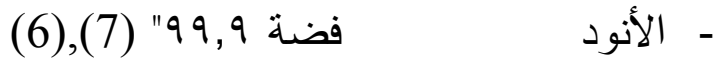

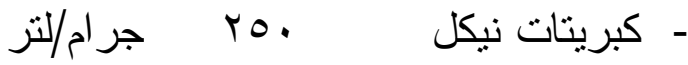

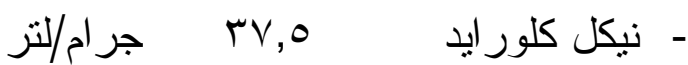

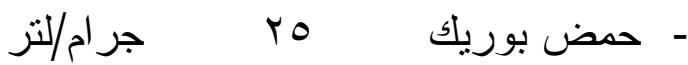

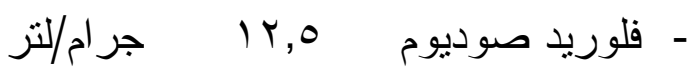

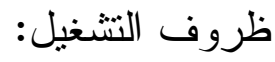

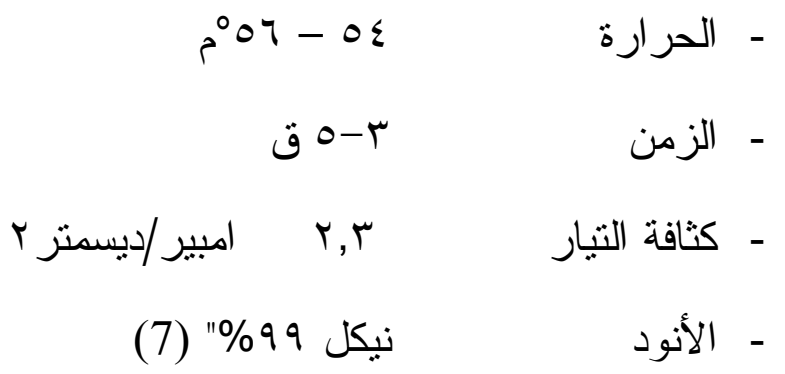




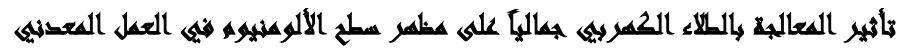

ملحوظة: تم استخدام محلول زينكات الصــوديوم لإكســاب

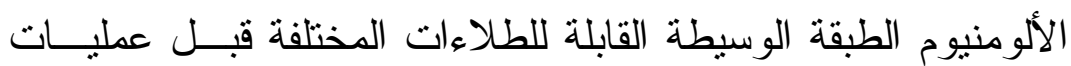

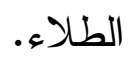

\section{رابعا: التجارب: Experiments}

- نم إجر اء التجارب المعلية باستخدام المحاليل السابقة من طلاء كهربـي بفلز النحاس الأحمر السيانيدي (القلوي) وطلاء النحاس الأصفر، وطلاء

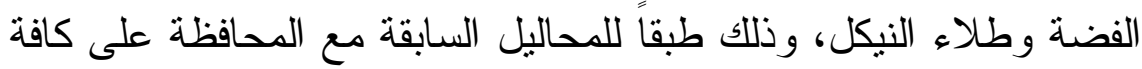

$$
\text { الثروط لكل محلول منها. }
$$

- نم استخدام الخلية الالكترونية مع استخدام التبار الكهربائي المستمر فـي

$$
\text { جميع التجارب. }
$$

$$
\text { - ـ تم استخدام محلول زينكات الصوديوم في جميع التجارب المعلية. }
$$

- ترسيب طبقة من زينكات الصوديوم على عينة الألومنيوم.

- البدء في ترسيب النحاس الأحمر القلوي طبقاً للمعادلة الدذكورة سابقاً في

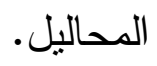

$$
\text { حجم العينة = } 10 \text { مفردة }
$$




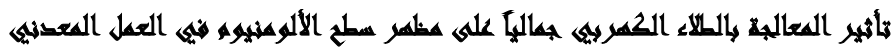

جدول رقم (1) يوضح تجربة طلاء الألومنيوم بالنحاس الأحمر القلوي

\begin{tabular}{|c|c|c|c|}
\hline مدى تأثز سطح & الحرارة درجة & التعريض ق & نوع المعالجة \\
\hline 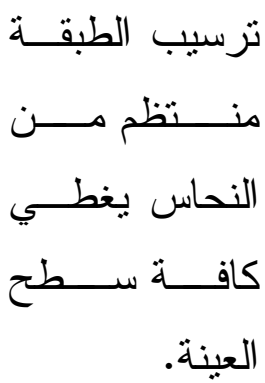 & $2^{0} 7 .-{ }^{\circ} \leq 0$ & r دقيقة & الومنيوم معالج \\
\hline
\end{tabular}

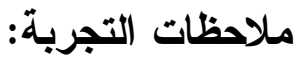

- - الطلاء ثابت ومتجانس ومنتظم.

- تم استخدام الهزازات الميكانيكية لتنشيط المحلول وتتشيط قوي التغطية.

r.تجارب الطلاء بالنحاس الأصفر:

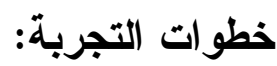

- ترسيب طبقة من زينكات الصوديوم على عينة الألو منيوم.

- مثم ترسيب طبقة من النحاس الأحمر القلوي.

- البدء في التجربة طبقاً للمعادلة الدذكورة سابقاً.

حجم العينة = 10 مفردة. 


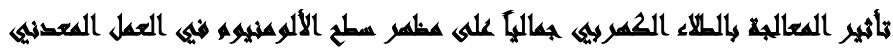

جدول رقم (Y) يوضح تجربة طلاء الألومنيوم بالنحاس الأصفر القلوي

\begin{tabular}{|c|c|c|c|}
\hline مدى نأثر سطح & الحر ارة & زمن التعريض & نوع المعالجة \\
\hline 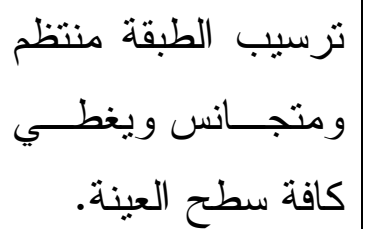 & $\begin{array}{l}-{ }^{\circ} \varepsilon . \\
0.0 .\end{array}$ & r - Tق & بطبقة وسيطة الومنيوم معالج \\
\hline
\end{tabular}

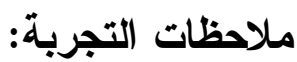

- الطبقة المرسبة شديدة الالتصاق ومتجانسة وثابتة ومنتظمة.

- تثبيت طبقة الطلاء من سبيكة النحاس الأصفر باستخدام محلول صوديوم

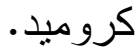

r.تجارب الطلاء بالفضة القلوية:

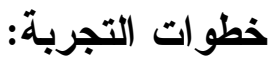

- ترسيب طبقة رقيقة من زينكات الصوديوم على عينة الألومنيوم.

- ثم ترسيب طبقة من النحاس الأحمر القلوي على طبقة زينكات الصوديوم.

- البدء في التجربة طبقاً للمعادلة المذكورة سابقاً في الدحاليل.

حجم العينة = 10 مفردة 


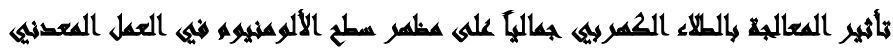

جدول رقم (r) يوضح تجربة طلاء الألومنيوم بالفضة القلوية

\begin{tabular}{|c|c|c|c|}
\hline مدى تأثز سطح & الحرارة & التعريض ق زمن & نوع المعالجة \\
\hline 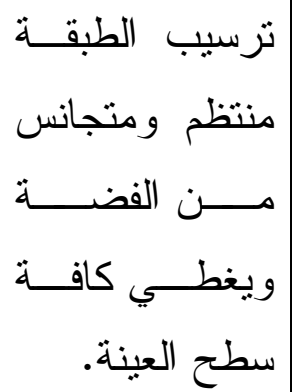 & $\rho^{\circ} \circ \mathrm{V}$ & ا ق & 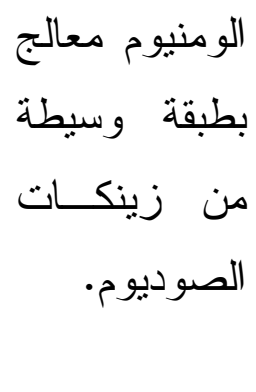 \\
\hline
\end{tabular}

ملاحظات التجربة: تم ترسيب طبقــة مــن الفضـــة متجانســة ومنتظمة السمك.

ع ـ تجارب الطلاء بالنيكل:

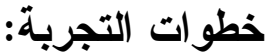

- ترسيب طبقة من زينكات الصوديوم على سطح الألومنيوم. - مثر ترسيب طبقة من النحاس الأحمر القلوي.

- ثم البدء في التجربة طبقاً للمعادلة المذكورة سابقاً في المحاليل. 


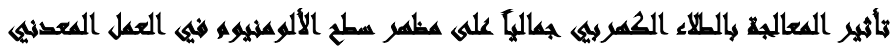

جدول رقم (乏) يوضح تجربة طلاء الألو منيوم بالنيكل

\begin{tabular}{|c|c|c|c|}
\hline مدى تأثز سطح & الحر درجة & التعريض ق زمن & نوع المعالجة \\
\hline 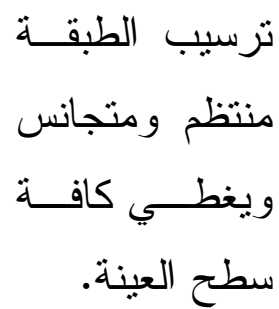 & م07-0 & $0-r$ & الومنيوم معالج \\
\hline
\end{tabular}

ملاحظات التجربة: طبقة الطلاء ثابتة ومتجانسة ومنتظمة السمك.

\section{خامساً: التطبيقات القنية:}

تم تطبيق بعض النماذج الفنبة باستخدام عمليات الطلاء الكهربي

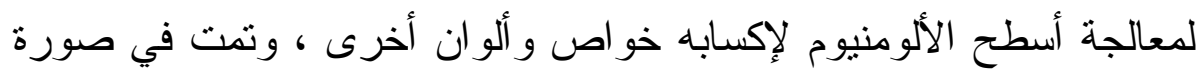

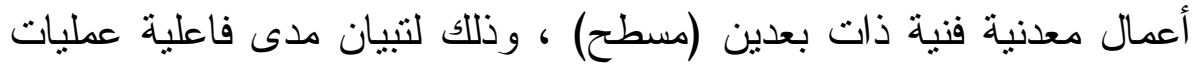

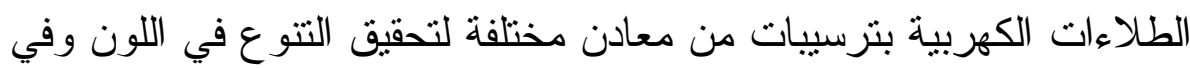

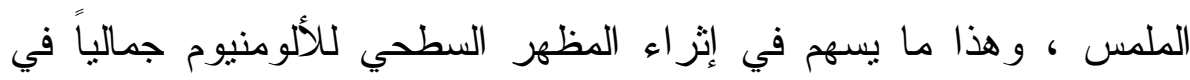

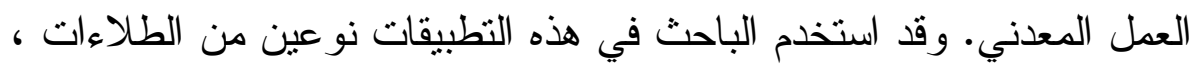
وهما الطلاء بالنحاس الأحمر القلوي ، و النحاس الأصفر القلوي، وذللك

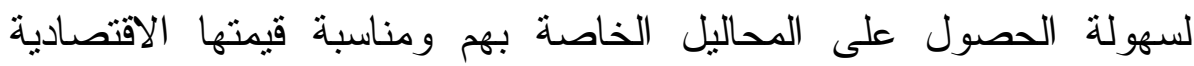
لمجال أثغال المعادن دوناً عن المحاليل الخاصة بأنو اع الطلاءات الأخرى. 


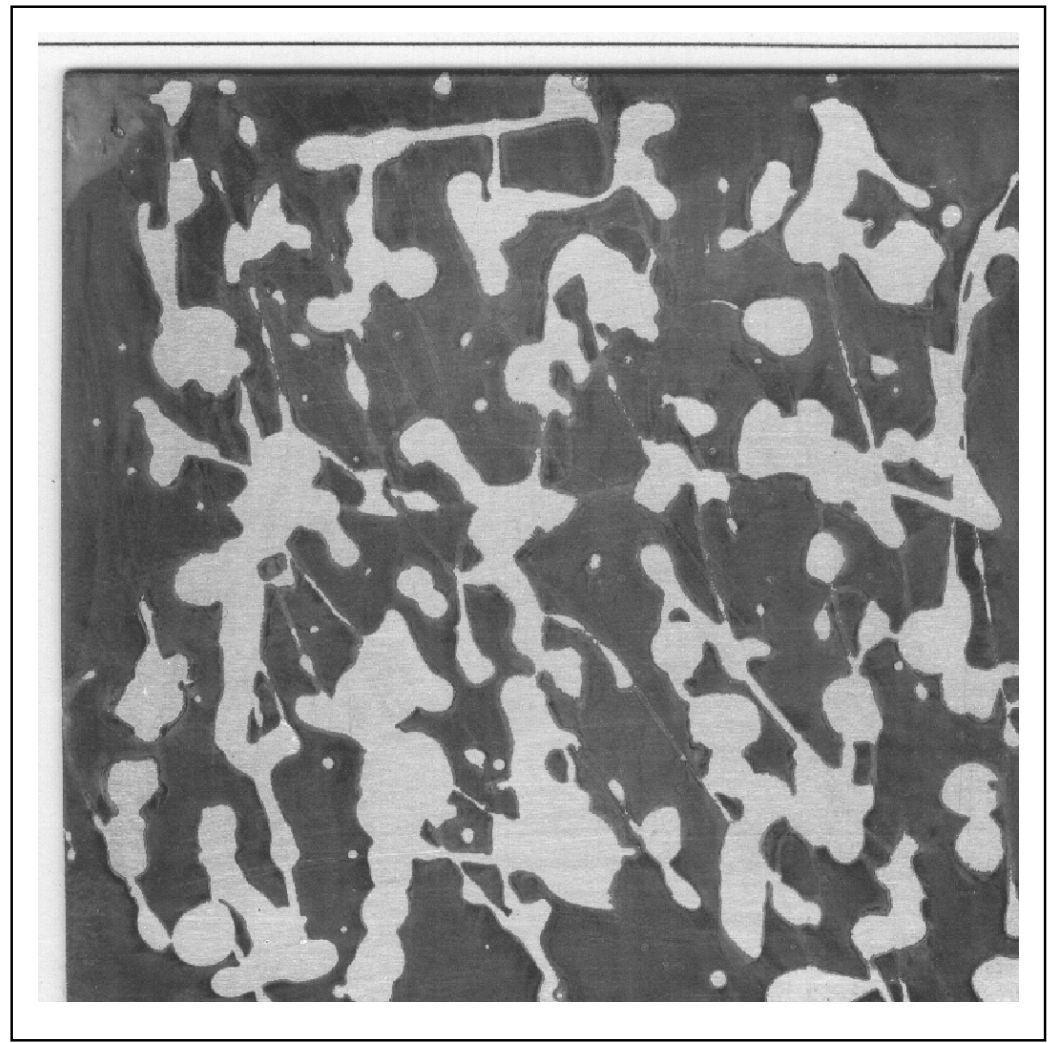

تطبيق رقم (1)

$$
\begin{aligned}
& \text { ألومونيوم } \\
& \text { معدن الأساس : } \\
& \text { نحاس احمر قلوي } \\
& \text { الطلاء الكهربي المستخدم: }
\end{aligned}
$$

الألوان الناتجة عن عملية الطلاء: اللون الأحمر النحاسي ، و اللون

$$
\text { الأبيض الفضي (الألومنيوم). }
$$

القيمة الجمالية للمظهر السطحي الناتج: تداخل لون النحاس الأحمر مع اللون الأبيض الفضي للألومنبوم مع تحقيق

قيمة الإيقاع في المساحات بينهما. 


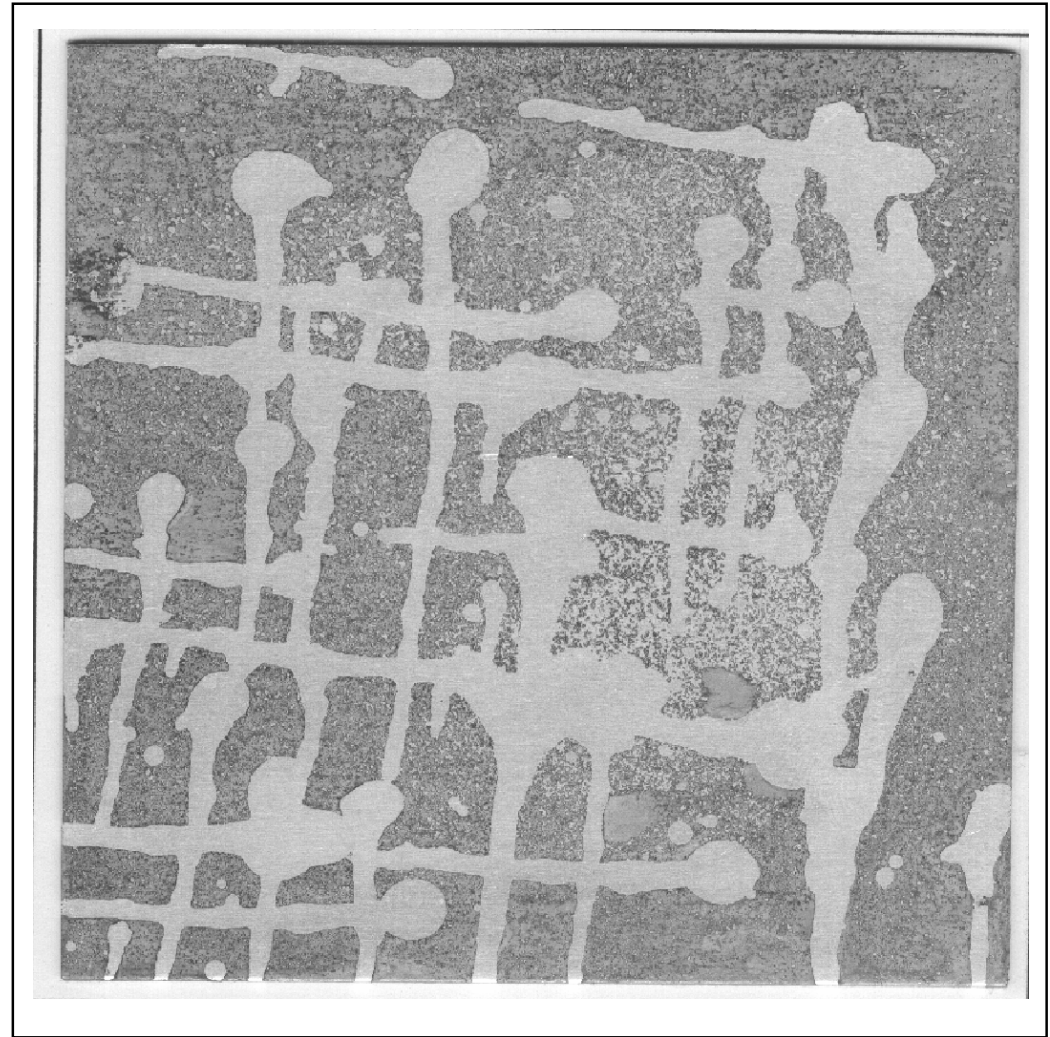

تطبيق رقم (ץ)

$$
\begin{aligned}
& \text { ألومونيوم }
\end{aligned}
$$

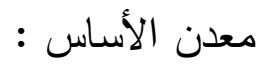

$$
\begin{aligned}
& \text { نحاس أصفر قلوي } \\
& \text { الطلاء الكهربي المستخدم: } \\
& \text { الألوان الناتجة عن عملية الطلاء: اللون الأصفر النحاسي ، و اللون } \\
& \text { الأبيض الفضي (الألومنيوم). } \\
& \text { القيمة الجمالية للمظهر السطحي الناتج: تداخل اللون الأصفر مع اللون } \\
& \text { الأبيض الفضي ، مما نتج عنه } \\
& \text { تاثير ات ملمسية ومساحات منتو عة. }
\end{aligned}
$$




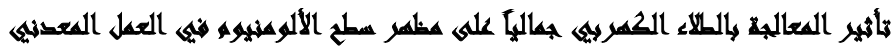

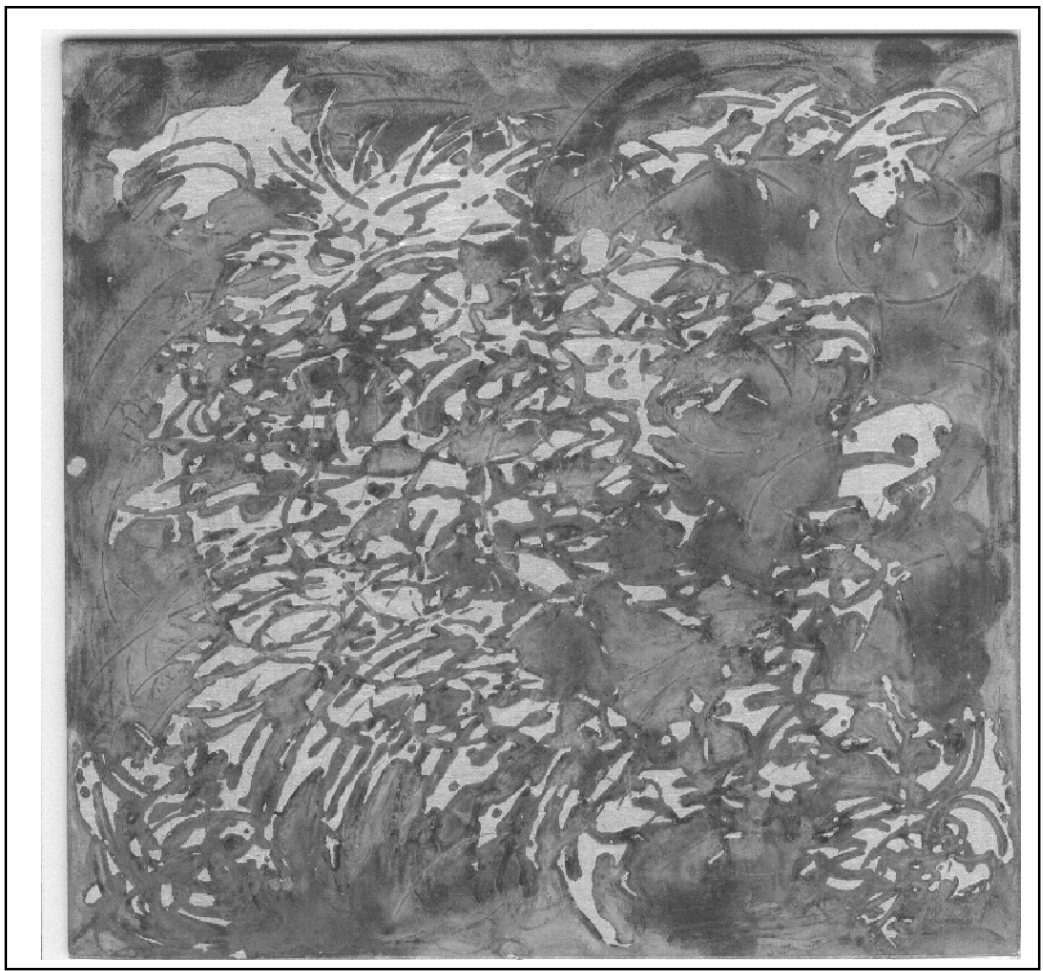

تطبيق رقم (ץ)

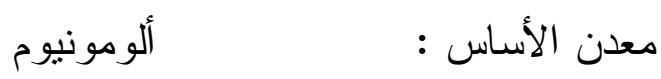

الطلاء الكهربي المستخدم: نحاس احمر قلوي ، ونحاس أصفر قلوي الألوان الناتجة عن عملية الطلاء:اللون الأحمر النحاسي القاتم، و الأصفر النحاسي الفاتح و القاتم ن و اللون الأبيض

$$
\text { الفضي (الألومنيوم). }
$$

القيمة الجمالية للمظهر السطحي الناتج: تداخلات لونية مختلفة مما نتج عنها

التتوع في الخطوط،و المساحات اللونية ،

$$
\text { وتأثير ات ملمسية مثتو عة. }
$$




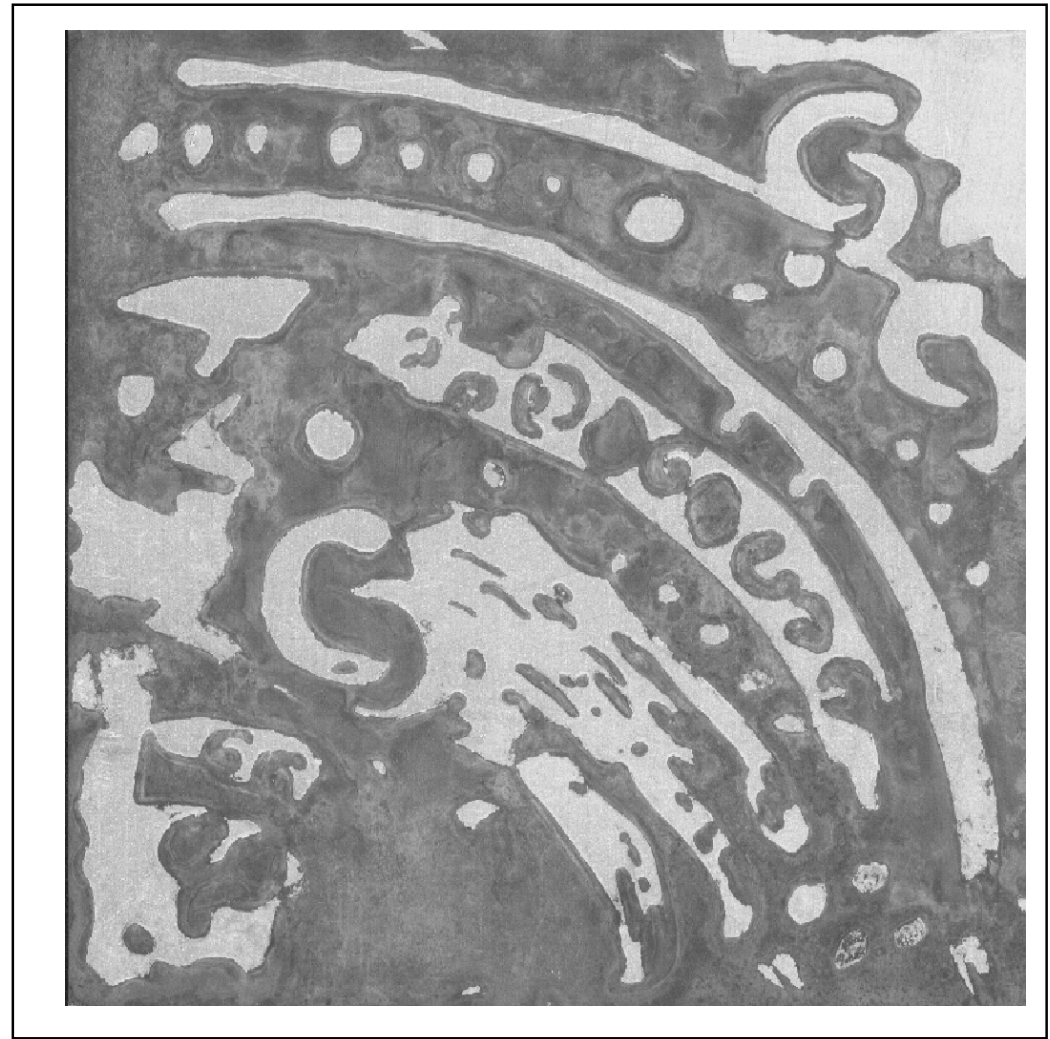

تطبيق رقم (؛)

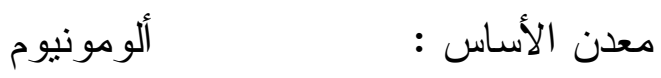

الطلاء الكهربي المستخدم: نحاس احمر قلوي ، ونحاس أصفر قلوي الألوان الناتجة عن عملية الطلاء:اللون الأحمر النحاسي ، و اللون الأصفر النحاسي و اللون الأبيض الفضي (الألومنيوم).

القيمة الجمالية للمظهر السطحي الناتج: تداخل في الألوان ونتج عنه تباين في المساحات اللونية ، وتأثير ات ملمسية متتو عة،

$$
\text { وشفافية بين الألوان ، وتدرج لوني بسيط. }
$$




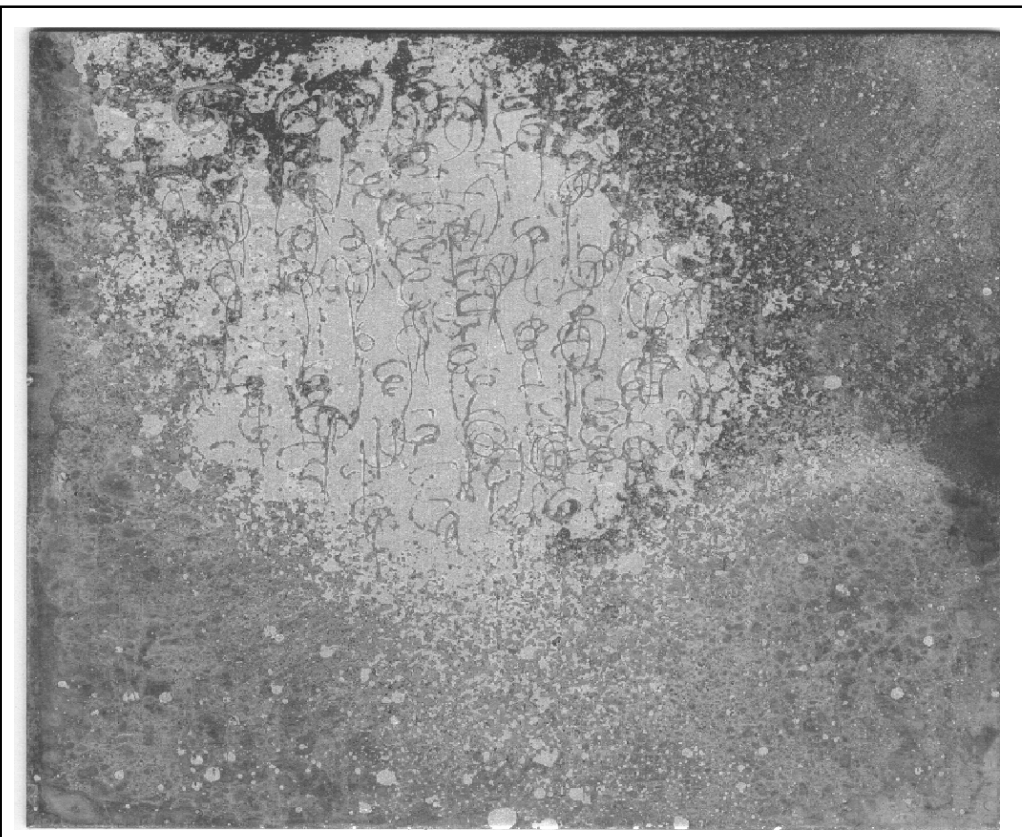

تطبيق رقم (0)

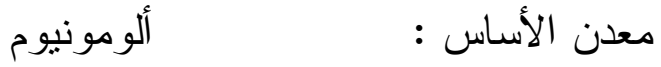

الطلاء الكهربي المستخدم: نحاس احمر قلوي ، ونحاس أصفر قلوي الألوان الناتجة عن عملية الطلاء:اللون الأحمر النحاسي ، و اللون الأصفر النحاسي القاتم المائل إلى الأخضر ، و اللون

$$
\text { الأبيض الفضي (الألومنيوم). }
$$

القيمة الجمالية للمظهر السطحي الناتج: تداخلات لونية متعددة ، وتأثنر ات ملمسية منتو عة ومتعددة ، وخطوط منتو عة

عديدة ، و التباين بين الألو ان المختلفة ،

$$
\text { و التدرج اللوني البسيط. }
$$


ا- ثبوت صلاحية استخدام زينكــات الصـــوديوم كمـــادة وســيطة يقبلهـــا الألومنيوم للترسيب عليه بالطلاءات التالية المختلفة.

r- ثبوت صلاحية امكانية الترسيب بالطلاء الكهربي بطبقة مــن النحــاس الأحمر وطبقة من النحاس الأصفر القلوي وطبقة من الفضة وطبقة مـنـ النيكل على معدن الألومنيوم المعالج بترسيب طبقة رقيقة مــن زينكـات

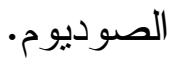

ب- جميع الطبقات الفلزية الرقيقة المترسبة على سطح الألومنيــوم المعــالج بزينكات الصوديوم متجانسة وشديدة الالتصاق ومنتظمة السمك. ع - ثبوت صلاحية الجمع بين ترسيبات مختلفة لمعادن مختلفة على الســطح

$$
\text { الو احد في الألومنيوم • }
$$

0- أن معالجة أسطح الألومنيوم بالطلاءات الكهربية المختلفة يكسب مظهره

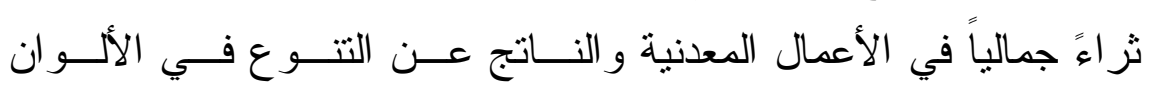
و الملامس. 
المراجع References

أولاً: المراجع العربية: - أع

أ. ماليشيف، ج. نيكو لاييف، ي. شوفالوف: تكنولوجيــا المعـادن، دار

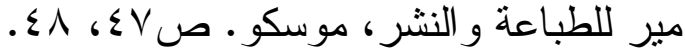

أنور محمود عبدالو احد: موسوعة النقافة العلمية، دار الكتاب الجديــــ

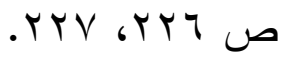

سعيد عبدالغفار : تكنولوجيا الألومنيــوم، ترجمـــة أنــور عبدالواحــد،

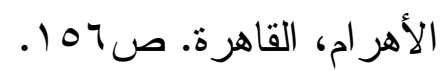

محمد محمود عبداللطيف: المعالجات السطحية و أثزرها علــى مظهـر

المنتج السياحي المعدني، رسالة دكتور اه غير منشـــورة، كليــة الفنـــون

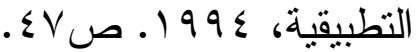

$$
\begin{aligned}
& \text { ثانياً: المراجع الأجنبية: }
\end{aligned}
$$

(5) American National Standards, ANSI/ASTM, standard recommended practice for preparation of copper and copper base alloy for electroplating, June, 26, 1997, P.426, P.455.

(6)E. A Ollarad, Introductory: Electroplating, Robert Draper LTD, Teddington U.K., 1999, P.144, P.149.

(7) Samuel Field, and A. Dudley Weill, Electroplat London, SIR ISSAC pitman asons LTD. Sixth Edition, 1997; P.311-314-502-503-512. 